\title{
Uma Visão da Vida Cultural Portuguesa
}

LELIA PARREIRA DUARTE

O Conselho da Comunidade Portuguesa de Minas Gerais enviou-me, na qualidade de delegada, ao $1^{\circ}$ Congresso das Comunidades Portuguesas, realizado em Lisboa, de 5 a 10 de junho de 1981. Foi uma oportunidade de conhecer diretamente o emigrante português e seus problemas, e de ter uma visāo da vida cultural dos remanescentes do "peito ilustre lusitano a quem Neptuno e Marte obedeceram", e que vivem dobrados "ao peso da História, carregando-a de facto, e que remédio - indias, naufrágios, cruzes de padrāo (as mais pesadas)".

Os emigrantes portugueses encarnam, a meu ver, aquela tendência dialética do espírito lusitano: um amor profundo e sentimental à terra e, ao mesmo tempo, um desejo heróico de afastar-se dela e conquistar o mundo. Eles continuam uma tradição iniciada com os séculos de luta para conquista do território aos mouros, a expansāo ultramarina, as viagens comerciais, as colonizaçōes. Representam, portanto, a luta externa para construir e manter arrumada a casa, e isso se manifesta concretamente no grande número de emigrantes que lutam no exterior durante todo o ano para voltar nas férias à Pátria, onde mantêm a sua casa de repouso, o seu refúgio da luta. Assim, Portugal é uma terra feminina: no sentido real é um país onde sempre predominaram as mulheres viúvas de mortos ou de vivos; no sentido místico, configura o universo feminino que, no dizer de Phillipe Sellier, representa o repouso do guerreiro, do herói. 
Parece que a intenção do congresso era proporcionar aos legados a oportunidade de discutir os problemas da emigração e, ao mesmo tempo, trazê-los sentimentalmente a um mergulho reconfortante nas tradiçōes da Pátria. Assim é que constavam da programação touradas, espetáculos folclóricos, uma exposição fotográfica intitulada "Portugal, um pequeno país cheio de riquezas", visita com um belo almoço ao mosteiro de Alcobaça, onde estão os túmulos de D. Pedro e Inês de Castro, e visita a Nazaré e ao santuário de Fátima.

Espetáculo completo, com as belíssimas indumentárias bordadas, os elegantes cavaleiros em seus animais bem treinados, a tourada portuguesa, especialmente depois de sua democratização, é típica de um povo marcado pelo espírito de heroísmo. Herói é aquele que caminha desassombradamente ao encontro da morte: intimamente nāo acredita que vá morrer, segundo Ernest Becker. Parece ser esta a coragem que leva os forcados (representantes do povo) a "pegar o touro à unha", depois de os cavaleiros (representantes da aristocracia) cravarem uma série de bandarilhas ao pescoço da fera, cada vez mais enfurecida e estimulada. Aquele que se adianta a grupo e desafia o touro, com a voz e a atitude, realmente parece encarnar o desejo heróico de imortalidade. $\mathbf{E}$ não é a tentativa frustrada de vencer os 600 quilos de fúria que o faz desistir. Vi, por duas vezes, o forcado ferido insistir para, na terceira vez, subjugar o touro.

Ao jantar típico com espetáculo folclórico não pude comparecer. Era no mesmo horário (domingo à noite) o programa cultural ao vivo de Eduardo Prado Coelho e Fernando Assis Pacheco, na televisão. Manuel Viqueira, que publicou recentemente em Espanha uma edição bilinguie de Fernando Pessoa, e eu, representando o Centro de Estudos Portugueses da Faculdade de Letras da UFMG, éramos os convidados. A conversa, informal e descontraída, foi entremeada de belos poemas, previamente gravados, de livros recentemente lançados: Ruy Cinatti - 56 poemas, António Osório - O lugar do amor, Herberto Hélder, Poesia toda, Joaquim Magalhães, Os dias, pequenos charcos, João Miguel Fernandes Jorge, $O$ roubador de água. 
Essa foi uma das apresentaçōes de poesia a que tive oportunidade de assistir; vi depois um belíssimo recital de poesia erótica, na "boite" Drogaria (realmente montada em uma antiga farmácia). Acompanhado por músicas ao piano e pela projeção de artísticos "slides", com intenção de, através de som/imagem, lembrar a conjugação iantra/mantra, o declamador falou poemas de Maria Teresa Horta, Melo e Castro, Herberto Hélder, Pedro Homem de Melo, Jorge de Sena, António Boto, António Nobre, David Mourāo-Ferreira, José Régio e o "Hino ao noivado", de Fernando Pessoa, em tradução de Natália Correia. Assisti ainda, na Associação Portuguesa de Escritores, à representação dos poemas do último livro de António Ramos Rosa.

A promoção da poesia e da publicação portuguesa em geral pareceu-me grande. Visitei a imensa feira do livro, de Lisboa, armada no parque Eduardo VII, onde conheci a bela cabeça branca de José Gomes Ferreira, o decano dos poetas portugueses". Tive oportunidade de ver, depois, a feira do livro na cidade do Porto. Muito movimentadas, essas feiras pareciam mostrar um grande interesse pelo livro, em Portugal, embora, segundo Eduardo Prado Coelho, as editoras portuguesas vivam atualmente uma grande crise.

O contato direto com determinado espaço cultural é sempre facilitado quando nos conduz um iniciado nesse espaço sagrado. Mais uma vez comprovou-se esse princípio das relaçōes humanas, quando o auxílio de Maria Lúcia Lepecki, aquela mineira de Araxá, doutora e docente-livre pela UFMG, e atualmente catedrática do Departamento de Literatura da Universidade de Lisboa, possibilitou-me o diálogo com vários escritores portugueses, apesar do reduzido tempo disponível.

Por seu intermédio conheci pessoalmente David Mourão Ferreira, José Cardoso Pires, Fernando Namora, Egito Gonçalves, José Gomes Ferreira, Wanda Ramos, Urbano Tavares Rodrigues. Foi através de seu auxilio que consegui falar com Isabel da Nóbrega e José Saramago, com Natália Correia e Fernando Grade, com Matilde Rosa Araújo e Maria Alberta Menéres, com Vitor Silva Tavares e António Torrado, com E.M. de Melo e Castro e Salvato Teles de Menezes (este não pôde, infelizmente e apesar de toda a sua boa vontade, conseguir-me uma entrevista com Carlos de Oliveira, que 
estava muito doente e faleceu pouco tempo depois). Lepecki faz a major propaganda de nosso trabalho no Centro de Estudos Portugueses da Faculdade de Letras da Universidade Federal de Minas Gerais, o que torna as pessoas receptivas e dispostas ao diálogo.

Estive com Jacinto do Prado Coelho, e Luís Amaro, a quem visitei na direção da Colóquio/Letras. O primeiro trabalha atualmente na edição do Livro do Desassossego, a ser publicado ainda este ano, em dois volumes. "A dificuldade está em decifrar os manuscritos, que são de muito interesse, há fragmentos muito elaborados", diz o crítico literário, que prepara também nova edição de seu estudo sobre Camilo, agora em dois volumes. $O$ professor falou de seu trabalho com a obra de Camões e Fernando Pessoa, na Pós-Graduação da Faculdade de Letras, e da influência deste último autor na literatura portuguesa contemporânea, por exemplo em Augusto Abelaira e Vergílio Ferreira.

$\mathrm{Na}$ Fundação Calouste Gulbenkian visitei ainda o Dr. José Blanco, dedicado amigo do Centro de Estudos Portugueses, que acaba de enviar à biblioteca do CESP uma série de publicações do mais alto interesse. A Fundação estuda atualmente a possibilidade de contribuir para o financiamento da publicação dos trabalhos apresentados na III Semana de Estudos Camonianos, comemorativa do IV Centenário de morte do Poeta. Estive ainda com a simpatia de Maria Clara Farinha, que tantas vezes já nos tem prestado sua colaboração amiga.

Visitei o Dr. Fernando de Melo Moser, no Instituto de Cultura e Língua Portuguesa, instituição que também tem dado o maior apoio às atividades do CESP e estuda atualmente a possibilidade de nos enviar um Leitor.

Falei com Ana Hatherly (que promete para breve outro livro) e Almeida Faria, respectivamente secretária e presidente do PEN Clube, que gentilmente me proporcionaram a oportunidade de estar com vários escritores, num jantar do próprio PEN Clube, oportunidade em que se entregavam prêmios aos escritores António Ramos Rosa, Agustina Bessa-Luís e Jorge de Sena (homenagem póstuma). Almeida Faria contou que em três meses esgotou-se uma edição de 2.000 exemplares de Lusitânia; o romance já foi traduzido para o sueco e ele pretende publicar em 1982 outra obra de ficção. Trabalha 
em tese de doutoramento sobre Estética das Vanguardas, o que inclui o estudo do Modernismo brasileiro. Nessa oportunidade conheci Casimiro de Brito e E.M. de Melo e Castro, e revi a suavidade da cabeça branca e do cachimbo de Manuel Ferreira, bem como o ar pensativo de Jorge Listopad. O primeiro contou-me ter um livro em andamento, o segundo prometeu-me uma entrevista que não tive tempo de cobrar.

$\mathrm{Na}$ Associação Portuguesa de Escritores estive com Urbano Tavares Rodrigues, seu atual diretor, que está organizando o $2^{\circ}$ Congresso de Escritores Portugueses, a realizar-se em fevereiro próximo. Professor universitário, ficcionista e ensaista, Urbano Tavares Rodrigues preocupa-se em atuar na vida político-social portuguesa, tentando favorecer a formação de uma mentalidade crítica, especialmente nas novas geraçōes. Julga que seus livros mais importantes são Imitação da Felicidade e Casa de Correção, e talvez ainda Bastardos do sol, já traduzido em França, Alemanha, União Soviética e Polônia. Seu último romance é Desta água beberei, que mostra consequiências da revolução, especialmente em três tipos distintos de mulheres, que se transformaram após o 25 de abril. Tem em elaboração Oceano Oblíquo, conjunto de narrativas fantásticas e oníricas: diálogos do amor e da dificuldade de comunicação, acentuada num periodo de transição como o que se está vivendo. Trata-se de histórias intimistas, interiores, sinédoques de um tema político (a revolução, o desmontar da feira) que aparece constantemente, mesmo sem estar presente.

Na Associação estive também com José Saramago, autor do belissimo livro Viagem a Portugal, escrito a convite do Círculo de Leitores. Apresentando um roteiro de viagem, a obra reproduz escrita e visualmente as múltiplas imagens colhidas por uma sensibilidade marcada por determinada maneira de estar no mundo e ser português. Publicados 30.000 exemplares em março de 1981, o trabalho foi um sucesso completo. Outra obra importante de José Saramago é Que farei com este livro? (1980), escrita especialmente para o $4^{\circ}$ centenário de morte de Camōes. O Autor não se preocupou com os amores do poeta, mas com o escritor que tenta publicar sua epopéia e vê que o seu trabalho interessa por motivos políticos e não culturais. Sobre essa obra, diz José Saramago: "A peça 
resume-se na impossibilidade de diálogo entre a grande eloqüência representada pelo Poeta e o silêncio do poder. Significativamente, D. Sebastião é personagem mas não diz uma só palavra. $O$ trabalho foi compreendido pelo público, que teve reações sintomáticas, especialmente nos diálogos entre o poeta e o censor. $O$ encenador Joaquim Benite teve a feliz idéia de colocar Camões vestido como o público comum, enquanto os outros se vestiam à moda da época".

José Saramago publicou também em 1980 Levantado do Chāo ( $1^{\text {h }}$ edição em fevereiro e $2^{\text {a }} \mathrm{em}$ julho - prêmio Cidade de Lisboa de 1981), cujo enfoque sociológico acompanha os pontos de vista do Neo-Realismo, afastando-se entretanto desse movimento literário na estrutura e nos extremamente modernos processos de construção.

O escritor está empenhado agora em um trabalho novo. Trata-se de um romance que "cobre 1711 a 1739, cuja personagem central é o convento de Mafra, e que reflete o luxo, a megalomania da época do ouro e das pedras que vinham de Minas Gerais. Denuncia a beatice, a corrupção, a miséria e a sangria de um povo que é cúmplice, na sua ignorância".

Fernando Namora, que está mais que nunca entusiasmado com - Brasil, conta que, além da Editora Globo, também a Nórdica pretende editar todos os seus livros, muitos dos quais já se encontram traduzidos em aproximadamente vinte línguas. $O$ autor de Resposta a Matilde é um escritor preocupado com o problema da emigração portuguesa, assunto que pretende tratar em um projeto romanesco ambicioso. A seu ver, a mitologia da emigração é um fato em Portugal. O português tem necessidade de sair de seu país para se afirmar, julgando que o sucesso pode modificar sua vida, a da família e o próprio ambiente português. "A emigração para a Europa colocou os portugueses em contato com sociedades que ofereciam grandes contrastes com a sua cultura, em nivel individual e coletivo. Com o refluxo, chegou a Portugal essa civilização européia em decadência, embora evoluída. $O$ resultado foram muitos choques, de interesse sociológico e literário". Fernando Namora pretende também tratar o tema da guerra colonial, que não lhe parece sistematicamente desenvolvido na literatura portuguesa.

Recebi a amável visita de Vergílio Ferreira, que me trouxe Conta corrente 1 e 2, já em segunda edição. A primeira esgotou-se 
rapidamente, fato que o Autor explica pelo interesse político do livro, por sua "má língua", pela confidência nele existente, pela variedade constante de assuntos e temas, o que talvez o identifique com literatura de consumo. "Nenhum de meus livros teve o impacto deste", diz o escritor; "entretanto, não me reconheço nele, não autografei um único exemplar". Gostou muito do trabalho de Maria da Glória Padrão sobre a sua obra (publicação da Imprensa Nacional). A escritora " $\mathrm{fez}$ um arranjo de entrevistas que realizam um percurso biobibliográfico, com organização excelente e muito interessante. Eu forneci a lama e Maria da Glória Padrão fez o ninho; ela é uma estudiosa das minhas coisas, conhece-as muito melhor que eu".

Vergílio Ferreira julga que sua obra está pronta e que não há nada de novo a dizer. Talvez por isso seu novo romance Para sempre "avance com soluços de gago". Um trabalho iniciado que gostaria de completar, no gênero de Invocação ao meu corpo, é Um dia de verão, em que a dominante seria o quotidiano, mais a reflexão ensaística. Julga que Fernando Pessoa é o "último clássico da poesia", "tem um fio de discurso que não nos deixa perder", e conta que a revista Persona vai inaugurar a seção "Fernando Pessoa e..." com Fernando Pessoa e Vergílio Ferreira.

A seu ver, prosa e poesia portuguesa atuais se aproximam, através da valorização do significante. "Por isso essa literatura torna-se pouco legivel, não desperta adesão tão fácil, mas não tem sentido combater-se isso. Essa talvez seja uma etapa necessária: haja uma liquidação do romance para haver depois um retorno a uma maior legibilidade, a uma procura de maior adesão do leitor, com uma revalorizaçāo do significado. A própria crítica atual é de valorização do significante, e Eduardo Prado Coelho teve papel predominante nessa renovação crítica. A valorização desse elemento chega ao extremo nos poemas de Melo e Castro, cabeça dessa nova orientação poética. Sua poesia vai ao limite das palavras cruzadas, e lembra Mallarmé e os gregos, que se preocupavam com a imagem do poema. Melo e Castro preocupa-se com o visual, com a disposição das palavras na frase, 0 que se pode relacionar com a poesia concreta brasileira e com o trabalho poético de Ana Hatherly". 
Outra visita muito apreciada foi a de Álvaro Manuel Machado, com seu último livro de poesias, acabado de imprimir: Intimo rigor. Contou que seu estudo sobre Agustina Bessa-Luís (Arcádia, 1979), encontra-se esgotado. Apesar das (quase) inúmeras aulas que dá, inclusive na ilha da Madeira, semanalmente, Âlvaro Manuel Machado dirige a coleção Paralelo e prepara tese sobre Literatura Comparada, que provará não ter havido Romantismo em Portugal.

Conversei também com Fernando Grade, da Ed.Mic (Movimento de intervenção cultural). Trata-se de cooperativa editorial, com delegados em todas as províncias, com o objetivo de percorrer 0 pais, dinamizando o movimento cultural e divulgando a poesia moderna e as artes plásticas. Fernando Grade é o coordenador das atividades dos delegados, que fazem recitais nas aldeias, onde os livros são vendidos a preços populares; têm trato muito íntimo com a população, o que se reflete na poesia do movimento.

“O MIC iniciou-se com o Desintegracionismo (sinônimo de Espacialismo), nova moda literária que indica o amor transportado para o espaço, em dois níveis dialéticos: o da palavra e o da temática. Esse foi o último movimento literário surgido em Portugal, e ainda não está dissecado em nível acadêmico", diz Fernando Grade. Os integrantes do grupo foram Júlio António Salgueiro e Costa Mendes (já falecidos), Fernando Grade, Armando Ventura Ferreira, Hugo Beja e Mário Elias (desenhista). Editaram um livro/manifesto em 1965 (esgotado). Houve várias atividades não oficiais comemorativas dos 15 anos do Desintegracionismo, que continua apenas a nivel individual.

Numa corrida contra o tempo, fui depois do congresso ainda à cidade do Porto, com a sua arquitetura de séculos de história, belamente construída junto ao Douro. Até ali recebi a ajuda de Maria Lúcia Lepecki, que encarregou Egito Gonçalves de substitui-la. Cumprindo perfeitamente o papel de hierofante, o autor de Os pássaros mudam no outono exibiu-me a História, ao mostrar a cidade, Vila do Conde e Viana do Castelo, enquanto discorria sobre vida cultural antiga e moderna. Falou de sua produção poética, cujas duas vertentes foram definidas em 1952: lirismo amoroso mais consciência política, marcados por forte dose de surrealismo, arma poderosa de que não dispunham, então, os neo-realistas. Fazendo um 
"surrealismo de cabeça para baixo", julga Egito Gonçalves ter concorrido para a libertação da imaginação portuguesa. Ele se preocupa entretanto, em não ser prisioneiro de seu próprio estilo e considera encerrada sua primeira fase, com Os arquivos do silêncio. "Hoje venceu minha tendência lírica", diz o Poeta, que não se interessa pelo trabalho com a linguagem em si mesma, mas preocupa-se em saber "o quê e o por quê". Tradutor de poesia (chilena, húngara, grega), Egito Gonçalves publicou Poemas do búlgaro Nicola Vaptsarov, e promete para o próximo ano traduções de quatro poetas finlandeses.

Almoçamos com Fernando Guimarães e sua amável esposa. $\mathrm{O}$ autor de A poesia da Presença e o aparecimento do Neo-Realismo, cuja segunda edição acaba de sair, tem no prelo Poesia (1952-1980) e prepara um estudo sobre Simbolismo, Modernismo e Vanguardas, de 1890 até Concretismo e Experimentalismo. Pretende tratar de todas as principais revistas do período, inclusive as recentemente publicadas Sema e Nova Renascença.

De regresso a Lisboa visitei Natália Correia, de quem já dissera Claude Roy: "( . . ) a grande dama da literatura portuguesa, reinando em seu salão do século XVIII". Preocupada com o regime noturno, com a feminização da literatura, Natália Correia trabalha no momento, apaixonadamente, com o diário de Florbela Espanca, de modo especial com a dualidade ali existente entre castidade e sedução. A autora da Antologia da poesia erótica $e$ satírica afirma ter publicado tudo o que lhe apeteceu na época da censura em Portugal, e sente-se realizada com a peça que escreveu sob encomenda do Teatro Nacional para a comemoração do quarto centenário de morte de Camões, embora a mesma não tenha sido encenada, por problemas políticos. "Consegui colocar a linguagem no século XVI e no século $\mathrm{XX}$, o que foi um fenômeno e a grande originalidade que os leitores vêem na peça. Fico à vontade, porque tenho me dedicado à atualização do cancioneiro medieval, o que torna mais fácil a manipulação da língua, aproximando as distâncias lexicais. Erros meus, má fortuna, amor ardente é uma peça que pretende refletir a dimensão épica e lírica de Camões, elementos típica ou arquetipicamente portugueses: o homem da expansão e da introspecção, o homem das celestes prin- 
cesas e o frequientador das rameiras, estrelas inatingiveis e fado que se arrasta no lodo. Camões representa a loucura, o grande disparate português que é querer meter o mundo no grão de areia que é este pais, maravilhoso disparate que é a razão de ser deste país insensato. Mas pergunto: de que nos serve a sensatez num mundo em que ela, quando a presumir de lógica, de ciência, de ratio, inventa os instrumentos que podem destruir a humanidade? Neste caso, eu sou pela insensatez desse povo rural que, como os camponeses, se enamora das estrelas que contempla e não pode alcançar".

Natália Correia concorda com Gaspar Simões, que afirma ser a sua obra polêmica e barroca, pois para ela "o barroco é um dominio feminino: é luz e sombras, mostra-se e esconde-se para apanhar os planos patentes e recuados, daí ser polêmico, constituir poesia usurária de suas descobertas".

Com Melo e Castro tive oportunidade de conversar com calma. 0 Poeta está satisfeito com a receptividade de seus livros recentes: As vanguardas na poesia portuguesa do século $\mathrm{XX}$ e Essa critica louca, obra sem sistematização metodológica, que réne ensaios escritos ao longo de vinte anos. Trabalha atualmente em duas obras: revisão e atualização de $O$ próprio poético, a ser publicado desta vez pela Imprensa Nacional, com 0 título de $O$ projecto de poesia; o outro é para a Biblioteca Breve: crítica e teoria literária do século XX em Portugal. Tem ainda outro projeto: algo que represente um risco em termos de escrita e que deve sair ainda este ano pela editora \& Etc. A seção central do livro tem 45 poemas escritos com palavras que não existem. Outro trabalho que julga necessário, mas muito complexo e diversificado, é a sistematização da literatura portuguesa de 25 de abril em diante, com sua temática e seu tratamento da linguagem inteiramente novos.

Segundo o crítico, a poesia dessa época é de tom menor, intimista, suburbana; a ficção é mais importante, porque mais inovadora, e há várias tendências que poderiam ser reunidas em três grandes familias:

$1^{\text {A }}$ - As situações narradas motivam, conduzem e determinam o discurso narrativo. Fxemplos desse primeiro eixo são: Levantado do chão, de José Saramago, $O$ trinenfo da morte, de Augusto Abelaira, Insitânia, de Almeida Faria, Viagem de um pai e de um filho pelas 
meas da Amargura, de Batista Bastos, $O$ concerto das buzinas, de Virgilio Martinho, Os cus de Judas, de Lobo Antunes e Desta água beberei, de Urbano Tavares Rodrigues.

$2^{a}$ - As situações de escrita provocam a evolução do discurso narrativo, distinguindo-se aí duas atitudes: a) a escrita é em si própria o motor da invenção ou da ficção. Exemplos: Casas pardas, de Maria Velho da Costa, Nós outros, de Casimiro de Brito e Teresa Salema, Cancioneiro policial da menina Alzira, de Luís Sousa Costa, O Mosteiro, de Agustina Bessa-Luís, O silêncio, de Teolinda Gersão, Exercicio no futuro, de Américo Guerreiro de Sousa. b) a escrita é a recuperação de uma oralidade ou fala de um grupo social. Exemplos: $O$ que diz Molero, de Diniz Machado, A floresta em Bremerhaven, de Olga Gonçalves, Portuguex, de Armando Silva Carvalho, Watt, de Fernando Assis Pacheco, Os Lusiadas, de Manuel da Silva Ramos e Alface, $O$ dia dos prodígios, de Lídia Jorge.

$3^{a}$ - A natureza do narrado alia-se à pesquisa da escrita, não sendo dela dissociável. Exemplos: Finisterra, paisagem e povoamento, de Carlos de Oliveira, $O$ sabor das trevas, de José Gomes Ferreira, Percursos (do Luachimo ao Luena), de Wanda Ramos e $O$ elefante de Setrai, de José Alberto Marques.

Na primeira família o discurso narrativo é altamente emotivo, diz Melo e Castro. "O referente é exterior ao discurso e igual ao narrado, enquanto na segunda familia o referente é a própria escrita ou oralidade específica de um determinado grupo social. $\mathrm{Na}$ terceira familia combinam-se a inovação da escrita e a carga ideológica, sendo o referente a própria escrita em relação estrutural com o concepto da realidade que incorpora". O crítico pretende, em breve, desenvolver essas idéias em ensaio a publicar.

Quanto à poesia, Melo e Castro considera que a época é de consolidação de tendências que foram vanguarda há vinte anos. Diz que "surgiram recentemente várias revistas de jovens poetas, que não conseguiram sobreviver; o pior é que acabaram por não corresponder a nenhuma posição nova, não tinham programa".

Segundo Eduardo Prado Coelho, esse problema é resultado de dispersão, inexistência de um sentimento acentuado de geração, que marcou tradicionalmente a literatura portuguesa. $O$ autor de $A$ letra 
litoral julga que há escritores tradicionais a serem contestados nos dias de hoje, mas que apenas uma geração que se afirmasse poderia contestá-los. Mesmo uma publicação importante nesse sentido como é o J.L. (publicação quinzenal, atualmente em seu $16^{\circ}$ número), um jornal do que existe, e que procura ser uma presença que dá conta do que acontece no mundo cultural, é reverencioso com relação aos valores já instituídos. Há, entretanto, obras novas de muito valor, segundo o crítico: $O$ mosteiro, de Agustina BessaLuís, $O$ silêncio, de Teolinda Gersão, 0 dia dos prodígios, de Lídia Jorge.

Eduardo Prado Coelho lembra que foi criado o prêmio Nacional de Cultura para tentar revelar novos valores, com a intençäo de valorizar a crítica de jornais. O premiado foi João Gaspar Simōes, o que indica, a seu ver, uma certa apatia cultural.

Também Egito Gonçalves pensa que não existe a necessária nova geração de autores portugueses, o que atribui a dois fatores: problemas financeiros (editoriais) e academismo, incapacidade de renovação. O poeta lembra que sua geração foi profundamente marcada pela guerra de Espanha, em que os de sua geração viram e previram o perigo de consolidação do fascismo.

Natália Correia fala de algo semelhante, quando diz que a literatura depois de 25 de abril não sofreu mudanças; as pessoas que não publicaram antes por causa da censura continuam a não publicar. Pensa a escritora que "a evolução dos acontecimentos às vezes castra-nos, enquanto que a repressão é estimulante e fecunda".

Para Vergilio Ferreira, a literatura de contestação antes de 25 de abril tinha sentido; depois dela os escritores ficaram despojados dessa temática.

Outro ponto de grande interesse na literatura portuguesa contemporânea é o da literatura infantil. Falei com três autores de livros para crianças: António Torrado, Maria Alberta Menéres e Matilde Rosa Araújo. Esta última preocupa-se, de modo especial, com a criança marcada pela emigração. Julga que a infância em Portugal é potencialmente amada, mas esquecida. "Há uma falsa consideração pela criança, e o problema é acrescido por sua necessidade de auxiliar na renda da família: nossa criança tem sido muito roubada". 
Trabalha, de modo especial pela formação de uma consciência crítica nas crianças, e assim como Maria Alberta Menéres, trabalha com as "Educadoras da Infância", orientando-as no estudo da literatura infantil e muitas vezes escrevendo histórias especiais para determinados grupos infantis, depois de observar suas necessidades.

A co-organizadora da Antologia da novissima poesia portuguesa, Maria Alberta Menéres, tem dirigido vários Encontros entre alunos, professores ou ambos simultaneamente, e os temas têm sido ensino, poesia e criatividade no ensino. Esse trabalho a apaixona e, de certa forma, continua sua atividade autora e apresentadora de programas infantis na Rádio Televisão Portuguesa. A escritora e poetisa sente-se realizada porque sua peça $O$ que é que acontecen na terra dos Procópios? (prêmio especial de teatro infantil da S.E.C. em 1979) foi vista por 52.000 crianças, que em suas escolas primárias fizeram trabalhos criativos sobre o espetáculo.

Dificuldades de horário me impediram de falar pessoalmente com António Torrado, o diretor da Editorial Plátano, excelente autor de livros infantis, na opinião de Jacinto do Prado Coelho e de Maria Lucia Lepecki, com quem conversei a respeito.

Falei (apenas por telefone, infelizmente), com Luiz Forjaz Trigueiros, escritor-critico que fez a resenha de Camōes \& Eça de Queirós, publicação do Centro de Estudos Portugueses, para a revista Colóquio/Letras.

Também rapidamente, por telefone, conversei com Oscar Lopes e Maria da Glória Padrão, no Porto. Oscar Lopes preocupa-se em organizar, com o INIC, uma bibliografia de todas as pesquisas que têm sido feitas em língua portuguesa. Vai publicar agora um livro de ensaios que está em preparo há três anos.

Maria da Glória Pàdrão está satisfeita com o sucesso de seu trabalho sobre Vergilio Ferreira e tem a publicar estudo crítico sibre Agustina Bessa-Luis. e uma interessada na literatura brasileira: prepara estudo comparativo entre obras de Clarice Lispector e Vergilio Ferreira, e também entre Cecília Meireles e a galega Rosalía de Castro.

E foi só. Tive que deixar para a próxima vez muitas outras entrevistas prometidas, assim como a satisfação do desejo de conhecer Portugal. Que haja uma próxima vez... 